\title{
Customer Classification in Indian Retail Sector- A Comparative Analysis of Various Machine Learning Approaches
}

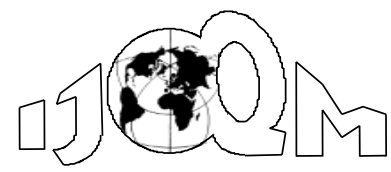

DOI: $10.46970 / 2020.26 .1 .1$

Volume 26, Number 1

March 2020, pp. 1-28

\author{
Sreekumar \\ Rourkela Institute of Management Studies \\ (sreekumar42003@yahoo.com) \\ Rema Gopalan \\ IFIM Business School \\ (gopalan.rema@gmail.com) \\ Mayuri Desai \\ MICA \\ (mayuridesai22@gmail.com) \\ D. P. Acharjya \\ VIT University \\ (dpacharjya@gmail.com)
}

The retail industry across the world is realizing that delivering high levels of service quality and achieving customer satisfaction is the key for a sustainable competitive advantage. Researchers have found positive relations between retail service quality dimensions and customer satisfaction. Identifying and classifying the retail customers as 'satisfied' or 'dissatisfied' according to the retail service quality dimensions would be useful to retailers in enabling strategic decision making in a competitive and dynamic environment. Retailers generate and collect a huge amount of customer data on daily transactions, customer-shopping history, goods transportation, consumption patterns, and service records in a relatively short period. The explosive growth of data requires a more efficient way to extract useful knowledge which can help the retailers to make better business decisions and to target customers who might be profitable to them. The concept of data mining has emerged as an effective technique for exploring large amounts of data to discover meaningful patterns and rules in various fields including retail. In this paper, the retail customers are classified into either 'satisfied' or 'dissatisfied' classes according to the retail service quality dimensions. The research presents a comparative study of popular classification techniques such as decision tree classifier and support vector machine using the $R$-studio software. The paper uses machine learning algorithms to assess the Indian retail service quality. The results would help the retail organizations to enhance their overall service quality and to target their marketing efforts at the right group of customers.

Keywords: Service Quality, Customer satisfaction, Decision tree, Data Mining, Classification, Support Vector Machine 


\section{Introduction}

Indian retailing today is at an interesting crossroads and has emerged as one of the most dynamic and fast-paced sectors. Reports on Indian retail industry reveals that an expanding middle class, rising incomes and spending power, a growing majority of youth in total population, rapid urbanization, and several other factors have shaped India's consumption pattern. A.T. Kearney, the well-known international management consultancy firm, annually ranks emerging market economies based on more than 25 macroeconomic and retail-specific variables through their global retail development index (GRDI). In 2017, in its 16th annual edition, it had placed India at the top position among 30 developing countries on ease of doing business in the retail sector. India's rapidly expanding economy, relaxation of FDI rules and the consumption boom are said to be the key drivers for India's top ranking in the GRDI. In today's competitive retail environment, the delivery of high service quality has long been treated as the basic retailing strategy. Service quality is important in every aspect of the business, and it helps in creating a positive image for the retailers' brand.

Additionally, the unique nature of retail service, improvements, and measurements of quality in retailing cannot be approached in the same way as that of the services are approached. It is necessary for retail service to look at quality from the perspective of services as well as goods and derive a set of items that accurately measure the different construct. Retail stores have evolved from providing only physical products that address consumers' needs to offering a solution centre that integrates the sale of both physical products and value-added services to attain competitive advantages. Cracking this code can lead to higher levels of customer retention, increased sales, and, in turn, improved profits. Besides, digitization, the introduction of different schemes and up-gradation of technology has seen the evolution of this space from unorganized trade to organized retail. Also, the study of retail sector classification using computational techniques is very less. Therefore, there is a need to study the retail customers' classification using some machine learning techniques. It, in turn, provides the factors affecting the classifications in the retail sector.

Due to heightened expectations, escalated competition, and rapid ingress of new business concepts and formats, companies are finding it difficult to retain their customers and remaining profitable (Rai and Srinivastava, 2012). Indian retail industry realizes that it must tailor its offerings to select customers, adjust and modify existent models, approaches, and processes to satisfy the needs of future customers to be successful and profitable. Traditionally, Indian retail companies have relied only on the differentiation of products and services to retain their customers and satisfy them. However, times have changed, consumer expectations of retailers have steadily raised while competitors have replicated shopping experiences, making it difficult for retailers to differentiate themselves in the eyes of their customers.

The area that receives foremost attention in this regard is delivering high levels of service quality and achieving customer satisfaction. Studies on service quality and customer satisfaction have gained considerable academic attention across the world. In today's world of intense competition, the key to sustainable competitive advantage lies in delivering high-quality service that will, in turn, result in satisfied customers 
(Shemwell et al., 1998). Service quality and customer satisfaction are inarguably the two core concepts that are the crux of the marketing theory and practice (Spreng and Mackoy, 1996). Customer satisfaction analysis is used for measuring customer satisfaction levels, taking counter actions for the low satisfaction points, and improving high satisfaction points (Aktepe, 2015). Quantitative measurement of customer satisfaction is one of the most important key performance indicators for companies and has become an integral part of effective customer relationship management (CRM).

In the meantime, the retail industry across the world is using information technology (IT) for generating, storing and analyzing mass-produced data not only for operational purposes but also for enabling strategic decision making to survive in a competitive and dynamic environment (Bose and Mahapatra, 2001). Nowadays, retailers generate and collect a considerable amount of data in a relatively short period. The explosive growth of data requires a more efficient way to extract useful knowledge which can help the retailers to make better business decisions. Thus, marketing is a significant area for applying data mining techniques (Shaw et al., 2001). A large amount of concealed, potential, value, and operational knowledge of enterprise are hidden in the original data. It is necessary to use data mining technology and new mining algorithms to mine customer classification information (Lee and Lin, 2000; Verhoef et al., 2010). Data mining techniques are expected to be a more effective tool for analyzing consumer behaviour. It is used by retail executives, employees and sometimes by channel partners to analyze information based on customer type, product category, and so forth to determine opportunities for tailored marketing efforts that would lead to better retailer performance (McDonnell et al., 2010).

However, data mining methods have their advantages and disadvantages. Hence, it is imperative to select the appropriate tool to mine database. Classification and mining of retail customers based on their satisfaction levels is not only the core content of CRM but also the key to winning the resource of retail customers in competition (Qian and Ju, 2009). In today's ever-increasing competitive business environment, it is imperative for a firm to target marketing efforts at the right group of customers. Many data mining tasks require classification of data into classes. In the present study, the retail customers can be classified into either 'satisfied' or 'dissatisfied' classes according to the retail service quality dimensions. A classifier provides a function that can classify a data instance into one of several predefined classes (Fayyad et al., 1996). At present, main methods such as association rule mining, category gathering, decision tree, are adopted in retail customer classification. In many cases, interpretability- the ability to understand the output of the induction algorithm is a crucial step in the design and analysis cycle (Kohavi, 1996). Researchers have identified that some classifiers are naturally easier to interpret than others.

In this context, the present study is a comparative study on the classification tools. Decision trees and support vector machine are used to classify the retail customers based on their satisfaction levels and to analyze the influence of retail service quality dimensions over customer satisfaction. The prime objective of choosing these two techniques depends on two factors, such as the number of responses and rate of 
convergence. Besides, Bayesian classification converges rapidly when there exists a conditional independence assumption. However, finding conditional independence in customers' responses is very difficult. There are so many factors that influence a customer while giving a response. At the same time, support vector machine and decision tree converge quickly when the number of responses is small.

The rest of the article is organized as follows. Following the introduction, the background of the research work is presented in Section 2. Section 3 presents the proposed design and research methodology followed by result analysis in Section 4 . Section 5 presents managerial implications, and the article is concluded in Section 6.

\section{Background of Research Work}

This section first gives an insight into the literature on service quality, retail service quality, applications of data mining techniques in marketing, and classification techniques used in data mining. Service quality is perceived as a tool to increase value for the consumer; as a means of positioning in a competitive environment (Mehta et al., 2000) and for ensuring consumer satisfaction (Sivadas, E., and BakerPrewitt, 2000), retention, and patronage (Bedi, 2010). Existing research indicates that consumers satisfied with service quality are most likely to remain loyal (Wong and Sohal, 2003). To understand service quality, knowledge about the quality of goods is insufficient, as indicators can objectively measure it as durability and number of defects.

The popular scale SERVQUAL was the first pioneering work towards the measure of service quality (Berry et al., 1998). SERVQUAL has been employed to measure service quality across different countries and various cultural backgrounds (Ladhari, 2008). Despite its usefulness in different "pure service" settings, the generalizability of SERVQUAL scale dimensions across different business settings has been in question. The applicability of SERVQUAL across different cultures is also an issue as SERVQUAL was developed in a Western environment and, due to cultural differences; it is likely that cultural factors influence its applicability (Parikh, 2006).

\subsection{Retail Service Quality and Customer Satisfaction}

Dabholkar et al. proposed retail service quality scale (RSQS) to overcome some of the limitations of SERVQUAL to be fully adapted and validated in a retail store that offers a mixture of services and merchandise (Dabholkar et al., 1996). RSQS is a performance-based measure of service quality but specific to the retail context (Kaul, 2007). Dabholkar et al. (1996) conducted qualitative research, and the findings were combined with existing literature and SERVQUAL, to form a basis for developing RSQS (Dabholkar et al., 1996). The model composes of five basic dimensions, such as physical aspects, reliability, personal interaction, problem-solving, and policy. Physical aspects deal with retail store appearance and store layout, whereas reliability deals with retailers keep to their promises and do the right things.

Personal interaction deals with retail store personnel are courteous, helpful, and inspire confidence in others, whereas problem-solving deals with retail store personnel are capable of handling returns and exchanges, customer's problem, and complaints. Finally, policy deals with the store's policy on merchandise quality, parking, operation hours, and credit cards. 
RSQS has been used by some researchers in measuring service quality in certain types of retailers such as department stores, supermarkets, and discount stores in Western and Eastern countries. Boschoff and Terblanche analyzed the reliability and validity of the RSQS in South African retail environment (Das et al., 2010). The instrument was found to be suitable for studying the service quality of the South African retail industry comprising of department stores, specialty stores, and hypermarkets that offered a mix of goods and services. Mehta et al. explored the usefulness of RSQS as a tool for measuring the service quality of different retail environments in Singapore (Mehta et al., 2000). The reliability of the scale for the five essential dimensions was tested in the context of supermarket and electronic goods retailers. The authors concluded that the RSQS scale was a better measure of service quality for a supermarket retailer than for an electronic goods retailer.

Similarly, Kim and Jin tried to determine whether RSQS could be validated in the context of discount stores for US and Korean customers (Kim and Jin, 2002). The findings showed that customer's perceptions of service quality do not similarly view service quality, nor do US and Korean customers of discount stores. In India, the applicability of RSQS was tested by Kaul in the context of apparel stores (Kaul, 2007). She concluded that the RSQS dimensions were not fitting rightly in the Indian context. Parikh studied the applicability of RSQS in Indian retail and found that the five dimensions are still useful, and the overall reliability of the instrument is quite acceptable (Parikh, 2006). He also suggested that once the factors are appropriately modified, the instrument can very well be utilized under the Indian conditions as well. Many researchers have investigated the relationship between service quality and customer satisfaction. The positive relationship between retail service quality and customer satisfaction has been confirmed in many cultures, and it explains part of the variance in customer loyalty (Lai et al., 2009).

In literature the terms service quality and customer satisfaction are used interchangeably. In the meantime, the researchers have established several distinctions between service quality and customer satisfaction. The most important aspect of customer satisfaction is the fact that it increases customer loyalty and profit, it also increases repeated buying behaviour and customer retention which is vital for the company's financial status. Many firms use customer satisfaction as a criterion for diagnosing product or service performance.

In this context it's very important for the managers to understand what drives the customer satisfaction and acts as an important input to formulate the business strategy. Many researchers have investigated the relationship between service quality and customer satisfaction. Though the positive relationship between retail service quality and customer satisfaction has been confirmed in many cultures, the studies on classification of retail customers as satisfied and dissatisfied based on retail service quality dimensions are scarce. Hence, the present study aims to classify the retail customers as 'satisfied' or 'dissatisfied' according to the retail service quality dimensions. To achieve the results the research presents a comparative study of popular classification techniques such as decision tree classifier and support vector machine using the R-studio software. 


\subsection{Data Mining Techniques in Marketing}

According to Linoff and Berry, data mining is defined as a business process for exploring large amounts of data to discover meaningful patterns and rules (Linoff and Berry, 2011). Association, classification, clustering, forecasting, regression, sequence discovery, and visualization cover the main data mining techniques (Ngai et al., 2009). These data mining techniques are implemented in many fields, depending on the aim of the business. Data mining applications in marketing include retail sales analysis, market basket analysis, product performance analysis, and market segmentation analysis (Bose and Mahapatra, 2001). The retail industry is a major application area for data mining since it collects huge amounts of data on sales, customer-shopping history, goods transportation, consumption patterns, and service records. Data mining allows retail store managers to identify their best customers, attract new customers, and inform them through mail marketing, and hence maximize their profitability. Retail data mining can help identify customer buying behaviors, discover customer shopping patterns and trends, improve the quality of customer service, achieve better customer retention and satisfaction, enhance goods consumption ratios, design more effective goods transportation and distribution policies, and reduce the cost of business (Han et al., 2011). The authors also mentioned that the broad areas of data mining applications in the retail industry include customer segmentation, establishing customer shopping behavior, customer retention, and analyze sales campaign. Sumathi and Sivanandam mentioned few applications of data mining in the retail industry such as design and construction of data warehouses based on the benefits of data mining; multidimensional analysis of sales, customers, products, time and region; analysis of the effectiveness of sales campaigns; customer retention-analysis of customer loyalty and purchase recommendation and cross-reference of items (Sumathi and Sivanandam, 2006).

\subsection{Classification in Data Mining}

Knowledge discovery in databases is the process of analyzing data from different perspectives and summarizing it into useful information. It consists of nine steps, and many researchers (Fayyad et al., 1996) is widely highlighting the step of data mining. There are two forms of data analysis, such as extracting models describing important classes or prediction of future data trends. Classification techniques are widely used in data mining to classify data among various classes. These techniques can be used to predict categorical class labels and classify data based on the training set and class labels, and it can also be used for classifying newly available data. Classification is a two-step process consisting of model construction by applying a classification algorithm on training data set and model validation. In model validation, the extracted model is tested against a predefined test dataset to measure the model trained performance and classification accuracy. There are many algorithms which are used for classification in data mining, and some of the commonly used classification techniques are decision tree classifiers, neural networks, support vector machines, and Naive Bayes classifiers. Further, these techniques are extended to $\mathrm{K}$ nearest neighbour $(\mathrm{KNN})$, case-based reasoning, genetic algorithm, rough set, and fuzzy set. Various hybrid methods are also used for classification purpose (Anitha and Acharjya, 2016; Acharjya and Anitha, 2017; Anitha and Acharjya, 2018). 


\section{Research Methodology}

The present paper has used the classification method of data mining to classify retail customers into the classes of satisfied and dissatisfied customers using decision tree and support vector machine algorithm. Both the implementations are carried out using programming language $\mathrm{R}$, a free software environment for statistical computing. A comparative study of both algorithms is being carried out in the paper. An overview of the proposed research methodology is depicted in Figure 1.

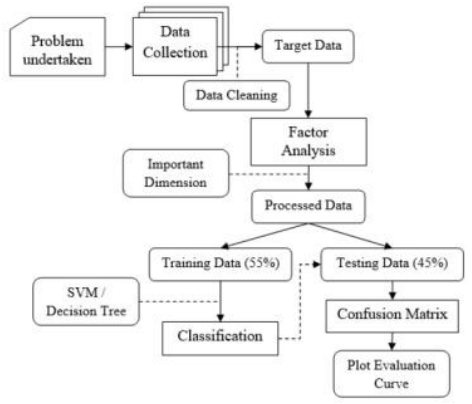

Figure 1 Overview of Proposed Research Methodology

The retail industry is arguably in a massive state of flux and transformation, which has been accelerated by new competitors and the massive global digital transformation. In the current scenario, consumers want to keep up with the latest trends but also crave convenience. Hence the popularity of subscription boxes and online shopping is high. With this in mind, the questionnaire is prepared and responses collected from retail shoppers. A total of 321 responses were collected on 28 scaled items beside the demographic variables. Factor analysis is carried out to identify the essential dimensions of retail service quality. To determine the dimensions of these stores and their relationships with the overall service quality, a questionnaire survey was conducted. The sample was selected from multiple apparel stores located in different areas of the State of Odisha. Simple random sampling was used to select the sample of 321 retail shoppers visiting retail clothing chain of stores of the state. The structured questionnaire is developed based on the literature review and a pilot survey which was conducted. The questionnaire is designed using fivepoint Likert scale, where 1 meant strong disagreement and 5 meant strong agreement with a particular risk source. The Statistical Package for Social Sciences (SPSS version 20.0) was used for data analysis purpose.

For reliability assessment of the scale Cronbach's Alpha is used. Reliability as we know is a measure of extend to which the scale produces consistent results, if repeated measurements are made. The Cronbach's Alpha varies from 0 to 1 and value less than 0.6 indicates unsatisfactory internal consistency reliability. The calculated value of Cronbach's Alpha is 0.861 shows the scale reliability. Next the Kaiser-Meyer-Olkin (KMO) measure of sampling adequacy is calculated. KMO is an index used to find out applicability of Factor Analysis. A high value between 0.5 to 1.0 indicates that Factor Analysis can be used. The calculated value of KMO is 0.731 indicates we can apply Factor Analysis. 
International J. of Opers. and Quant. Management

Table 1 Variables Considered for Research

\begin{tabular}{|c|c|c|c|c|}
\hline Factor & $\begin{array}{c}\text { Factor } \\
\text { Interpretation }\end{array}$ & Notation & Loading & Variables included in the factor \\
\hline \multirow[t]{2}{*}{$\mathrm{F} 1$} & \multirow{2}{*}{$\begin{array}{c}22.435 \\
\text { (Problem solving) }\end{array}$} & PS1 & 0.826 & $\begin{array}{l}\text { Employees of this store are able to handle } \\
\text { customer complaints directly and } \\
\text { immediately. }\end{array}$ \\
\hline & & PS2 & 0.540 & $\begin{array}{l}\text { When a customer has a problem, this store } \\
\text { shows a sincere interest in solving it. }\end{array}$ \\
\hline \multirow{3}{*}{ F2 } & \multirow{3}{*}{$\begin{array}{c}8.446 \\
\text { (Personal } \\
\text { interaction) }\end{array}$} & PI1 & 0.722 & $\begin{array}{l}\text { The behavior of employees in this store } \\
\text { instills confidence in customers. }\end{array}$ \\
\hline & & PI2 & 0.713 & $\begin{array}{l}\text { Employees in this store tell customers exactly } \\
\text { when services will be performed. }\end{array}$ \\
\hline & & PI3 & 0.619 & $\begin{array}{l}\text { Customers feel safe in their transactions with } \\
\text { this store. }\end{array}$ \\
\hline \multirow{2}{*}{ F3 } & \multirow{2}{*}{$\begin{array}{c}6.929 \\
\text { (Merchandise) }\end{array}$} & Mer1 & 0.535 & $\begin{array}{l}\text { This store has merchandise available when the } \\
\text { customers want it. }\end{array}$ \\
\hline & & Mer2 & 0.847 & This store offers high quality merchandise. \\
\hline \multirow{2}{*}{$\mathbf{F 4}$} & \multirow{2}{*}{$\begin{array}{c}6.260 \\
\text { (Physical aspects) }\end{array}$} & PA1 & 0.719 & $\begin{array}{l}\text { The store design enables customers to move } \\
\text { around with ease. }\end{array}$ \\
\hline & & PA2 & 0.717 & $\begin{array}{l}\text { This store has modern-looking equipment and } \\
\text { fixtures. }\end{array}$ \\
\hline \multirow{2}{*}{ F5 } & \multirow{2}{*}{$\begin{array}{c}5.960 \\
\text { (Reliability) }\end{array}$} & Rel1 & 0.770 & $\begin{array}{l}\text { This store provides its services at the time it } \\
\text { promises to do so. }\end{array}$ \\
\hline & & Rel2 & 0.694 & $\begin{array}{l}\text { The employees of this store act in the best } \\
\text { interest of the customers. }\end{array}$ \\
\hline \multirow{2}{*}{ F6 } & \multirow{2}{*}{$\begin{array}{c}4.963 \\
\text { (Convenience) }\end{array}$} & Con1 & 0.748 & $\begin{array}{l}\text { This store has operating hours convenient to } \\
\text { all their customers. }\end{array}$ \\
\hline & & Con2 & 0.706 & $\begin{array}{l}\text { This store provides plenty of convenient } \\
\text { parking for customers. }\end{array}$ \\
\hline \multirow{2}{*}{ F7 } & \multirow{2}{*}{$\begin{array}{c}4.547 \\
\text { (Transaction) }\end{array}$} & Tran1 & 0.866 & $\begin{array}{l}\text { This store insists on error-free sales } \\
\text { transactions and records. }\end{array}$ \\
\hline & & Tran2 & 0.777 & $\begin{array}{l}\text { This store provides online payment facility to } \\
\text { its customers. }\end{array}$ \\
\hline \multirow[t]{2}{*}{ F8 } & \multirow[t]{2}{*}{ Store policy } & SP1 & 0.765 & $\begin{array}{l}\text { This store has additional facilities such as trial } \\
\text { rooms, toilets, pay phones, and working } \\
\text { trolleys available for its customers. }\end{array}$ \\
\hline & & SP2 & 0.645 & $\begin{array}{l}\text { The price/quality ratio offered at this store is } \\
\text { reasonable. }\end{array}$ \\
\hline \multirow{5}{*}{\multicolumn{2}{|c|}{ Demographic }} & \multicolumn{2}{|c|}{ Age } & Age (Continuous Scale) \\
\hline & & \multicolumn{2}{|c|}{ Gender } & Gender (Male/Female) \\
\hline & & \multicolumn{2}{|c|}{ MI } & Monthly income (Continuous Scale) \\
\hline & & \multicolumn{2}{|c|}{ MS } & Marital status (Married / Unmarried) \\
\hline & & \multicolumn{2}{|c|}{ Occ } & $\begin{array}{l}\text { Occupation (Self-employed / Salaried / } \\
\text { Unemployed / Retired) }\end{array}$ \\
\hline
\end{tabular}


Variables that have factor loading more than the value of 0.5 or more are considered for the final study and are presented in Table 1. The eight dimensions which were identified as playing an essential role in retail service quality are problem-solving, personal interaction, merchandise, physical aspects, reliability, convenience, transaction, and store policy. All these dimensions and the composite scale reliability is found to more than 0.7 . Therefore, it is essential to think of the dimensions of these stores before making any analysis.

\subsection{Data Pre-Processing}

The raw data obtained does not give any information in the form it appears (Gupta et al., 2016). The raw data stored could contain errors due to multiple reasons like, missing data, inconsistencies that arise due to merging data, incorrect data entry procedures, and so on. Deriving meaningful information from the raw data requires pre-processing of data that converts real-time data into a computer-readable format. The pre-processing stage involves attribute selection, data cleaning, and data transformation (Deb and Liew, 2015; Rathi and Acharjya, 2018). This process starts with data collection, and then the required features or attributes have been selected from the raw data, ready for analysis. Then data cleaning was performed by eliminating the errors and missing values, with the correction of syntaxes. Finally, the data is prepared and transformed into a suitable and readable format for the datamining tool to generate.

\subsection{Decision Tree Classification}

A decision tree is a classification scheme that generates a tree and a set of rules, representing the model of different classes, from a given data set. The set of records available for developing classification methods is generally divided into two disjoint subsets - a training set and a testing set. The former is used for deriving the classifier, while the latter is used to measure the accuracy of the classifier. The accuracy of the classifier is determined by the percentage of the test examples that are correctly classified. A decision tree structure is made of the root, internal, and leaf nodes. It is a flow chart like a tree structure, where every internal node denotes a test condition on an attribute, each branch represents the result of the test condition, and each leaf node is assigned with a class label. The first node is the root node. A decision tree is constructed in a divide and conquer approach. Each path in decision tree forms a decision rule, and in general, it utilizes a greedy approach from top to bottom.

Decision tree classification technique is performed in two phases: tree building and tree pruning (Anyanwu and Shiva., 2009). Tree building is performed in a top-down approach. During this phase, the tree is recursively partitioned until all the data items belong to the same class label. It is very computationally intensive as the training dataset is traversed repeatedly. Tree pruning is done in a bottom-up manner. It is used to improve the prediction and classification accuracy of the algorithm by minimizing the over-fitting problem of the tree. The over-fitting problem in decision tree results in misclassification error. There are many decision tree-based algorithms like ID3, C4.5, C5.0, CART. These algorithms have the advantages of high classifying speed, strong learning ability, and simple construction. A decision tree is explained with an example as depicted in Figure 2. 


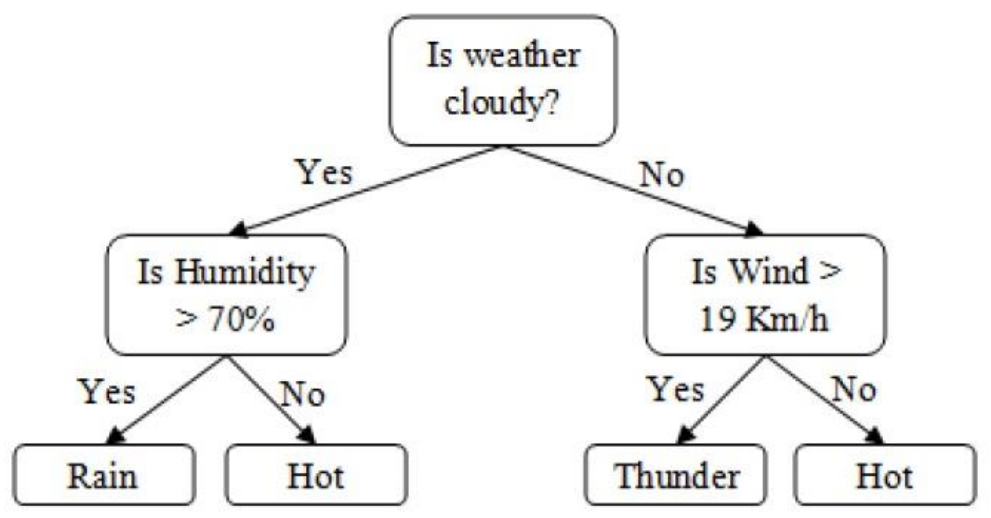

Figure 2 An Example of Decision Tree Classification

The example shows a weather forecasting process which deals with predicting whether the weather is sunny, rainy or thunder and the amount of humidity if it is sunny. This tree model can be applied to determine whether the atmosphere is suitable to play tennis or not. So, a person can easily find the present climate, and based on that decision can be made whether a match can be possible or not.

\subsection{Support Vector Machines}

Support vector machines (SVM) are a set of related supervised learning methods used for classification and regression and belong to a family of generalized linear classifiers (Boser et al., 1992). The foundations of SVM have been developed by Vapnik and gained popularity due to many promising features such as better empirical performance. The formulation uses the structural risk minimization (SRM) principle, which is superior, to traditional empirical risk minimization (ERM) principle, used by conventional neural networks (Burges, 1998). SRM minimizes an upper bound on the expected risk, whereas ERM minimizes the error on the training data. It is this difference which equips SVM with a greater ability to generalize, which is the goal in statistical learning. SVMs were developed to solve the classification problem, but recently they have been extended to solve regression problems (Vapnik, 1997).

In general, SVM can be defined as systems which use hypothesis space of a linear function in a high dimensional feature space, trained with a learning algorithm from optimization theory that implements a learning bias derived from statistical learning theory. The original form of SVM is a binary classifier where the output of the learned function is either positive or negative. The basic SVM deals with two-class problems in which the data are separated by a hyperplane defined by several support vectors. It can be considered to create a line or hyperplane between two sets of data for classification. Simultaneously, it attempts to place a linear boundary between the two different classes and orient it in such a way that the margin is maximized. Further, it tries to orient the boundary such that the distance between the boundary and the nearest data point in each class is maximal. The boundary is then placed in the middle of this margin between the two points. The nearest data points are used to 
define the margins and are known as support vectors. Once the support vectors are selected, the rest of the feature set can be discarded since the support vectors contain all the necessary information for the classifier. In general, cases, where the data is not linearly separated, SVM uses nonlinear machines to find a hyperplane that minimizes the number of errors for the training set. Since in many cases, no separating hyperplane exists or it could be worthwhile to misclassify a few observations to improve the classifying of the remaining ones, the task of margin maximization needs modifications. The support vector machine suggested by Cortes and Vapnik is such an extension of the maximal margin classifier (Cortes and Vapnik, 1995). The SVM classifier finds the maximal margin separating hyperplane for observations from the training data set transformed by $\phi$ into the space of the higher dimension (sometimes infinite) with the constraint on the number of misclassifications. The optimization problem which yields to that classifying rule is to minimize the Lagrangian

$$
L(\alpha)=\frac{1}{2 \alpha Q \alpha}-e^{\prime} \alpha
$$

Subject to $0 \leq \alpha_{i} \leq C$ and $y^{\prime} \alpha=0$, where e is the unity vector, $\mathrm{C}$ is the upper bound of the number of misclassifications (cost), Q is the matrix of $Q_{i j}=y_{i} y_{j} K\left(x_{i} x_{j}\right)$ and $K\left(x_{i} x_{j}\right)=\phi^{\prime}\left(x_{i}\right) \phi\left(x_{j}\right)$ is the kernel function, $i, j=1,2, \ldots, N$, where $\mathrm{N}$ is the number of support vectors. Due to the application of the kernel function, there is no need to obtain the exact form of the transformation. The solution of the optimization problem depends on a subset of vectors of featuresthe support vectors. The most common kernels are defined below where a, d, and $\gamma$ are the kernel functions' coefficients.

Linear: $\quad K\left(x_{i}, x_{j}\right)=x_{i}^{\prime} x_{j}$

Polynomial of deg reed: $K\left(x_{i}, x_{j}\right)=\left(\gamma x_{i}^{\prime} x_{j}+a\right)^{d}$

Radial basis :

$$
K\left(x_{i}, x_{j}\right)=\exp \left(\gamma\left|x_{i}-x_{j}\right|^{2}\right)
$$

Sigmoid :

$$
K\left(x_{i}, x_{j}\right)=\tanh \left(\gamma x_{i}^{\prime} x_{j}+a\right)
$$

The above kernels are used to transforming the linearly inseparable data into linearly separable one. The challenge of mapping the original non-linear observations into some higher dimensional space in which they become separable. Based on the problem in hand we can choose the appropriate kernel function.

An important issue in constructing the SVM classifier is the selection of parameters influencing the effectiveness and the generalization capability of the classifier: the cost parameter $C$ that determines the penalty for misclassifications, the kernel function, and kernel function's parameters, influencing the function shape or dimensionality. An overview of SVM classification is presented in Figure 3. 


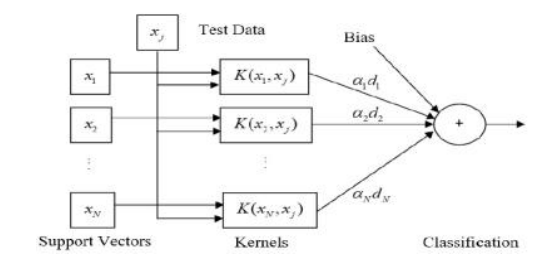

Figure 3 An Overview of SVM Classification

\section{Result Analysis}

The variables of retail service quality are analyzed by developing a code snippet in R-Studio separately for support vector machines and decision tree. The final results of the two models are compared, and the inferences are drawn. The models are analyzed for different values of cost $(C)$ and gamma $(\gamma)$ for each of the two classes viz. satisfied and dissatisfied. The data for the model is divided into a training and test dataset of $55 \%$ and $45 \%$ respectively. The training dataset is used to generate decision rules for the models. The test dataset is used to see how well the decision rule predicts new data. The complete dataset of 321 is divided into two classes, such as satisfied and dissatisfied. Each class contains 182 and 139 observations, respectively. The first 177 (55\%) of the observations is designated as the training set, whereas the remaining $144(45 \%)$ of the observations becomes the test dataset. Further, the analysis is carried out using both the SVM and decision tree model. Since the dataset contains very less data, it is not advisable to go for 10-fold crossvalidation. In such cases, each folder includes only 32 data, and getting inference from it is difficult. Therefore, standard data partition technique of $55 \%$ and $45 \%$ is selected.

\subsection{Analysis in Accordance with SVM}

SVM is a prediction model based on supervised classification, which makes it possible to recognize complex patterns in high-dimensional data sets (Cortes and Vapnik, 1995; Vapnik and Chervonenkis, 1974). R-project allows one to look through a relatively large space of SVM parameters to select their optimal values and to find the optimal model for the given kernels. The various steps involved in the analysis are given below.

1. Building SVM Model: The optimal values of SVM parameters, i.e., the cost parameter, the kernel function, and the kernel function's parameters, can be determined by iteratively training SVM models in various configurations and selecting the best model. Various parameters considered are SVM-Type: Cclassification; SVM-Kernel: radial; cost: $1 ; \gamma: 0.01315861$; number of support vectors: 206 with classes 0 and 1 .

The influence of a single training example is defined by $\gamma$. The low values have a 'far' reaching influence, while high values have a 'close' influence. The $\gamma$ parameters are the inverse of the radius of influence of samples selected by the model as support vectors. The $C$-parameter establishes a trade-off between misclassification of training examples and simplicity of the decision surface. A low $C$ value defines the smoothness of the decision surface, while a high $C$ value 
classifies all training examples correctly by giving the model freedom to select more samples as support vectors. The kernel functions return the inner product between two points in a suitable feature space, thus defining a notion of similarity, with a little computational cost even in very high-dimensional spaces. Commonly used kernels in SVMs are the linear kernel, Gaussian radial basis function (RBF) kernel, and polynomial kernel (Hornik, et al., 2006).

Further, classification results can be described with the confusion matrix of correct and incorrect classifications (Larose, 2014; Acharjya and Das, 2017). The columns represent the predicted classifications, and the rows represent the actual classifications, for all sessions in the test set. The confusion matrices for optimal SVM models with different kernel functions are presented in Table 2. The confusion matrix predicts 62 and 47 as correctly classified instances, while 26 and 9 are wrongly classified.

2. Model Predictions: As interpreted from the results presented in Table 3, the accuracy of the model is $75.40 \%$, while the sensitivity and specificity are 87.30 $\%$ and $63.8 \%$ respectively. It indicates that the model is an aggressive one, and it predicts that the customers are satisfied. The positive class defines in the classification problem is 0, i.e., satisfied. The kappa value is 0.5128 , which indicates a good fit. At $95 \%$ confidence interval, the predictions are $61.03 \%$ and $86.76 \%$ respectively for each of the two classes. The balanced accuracy for the model is 0.7585 .

3. Feature Selection: To build a better model, feature selection is being carried out. Figure 4 shows the feature importance plot. The top 5 important features include Age, MI, SP23, PI14, and Mer23.

4. New Model Development and Predictions for the Top Features: The new SVM model is developed considering the top features based on the variable importance plot. The 20 important variables were identified and were used for building the new model. The confusion matrices for the SVM new model with different kernel functions are presented in Table 4. The confusion matrix predicts 56 and 44 as correctly classified instances, while 29 and 15 are wrongly classified.

The accuracy of the model is $69.35 \%$, while the sensitivity and specificity are $79.07 \%$ and $60.17 \%$ respectively. It indicates that the model is an aggressive one, and it predicts that the customers are satisfied. The positive class defined in the classification problem is 0 , i.e., satisfied. The kappa value is 0.38 indicates that it is a good fit. At $95 \%$ confidence interval, the predictions are $54.56 \%$ and $81.73 \%$ respectively for each of the two classes. The balanced accuracy for the model is 0.6952. For better visualization, the results are presented in Table 5. The previous snippet shows that the overall accuracy of the model has dropped from $75.40 \%$ to $69.35 \%$. The sensitivity and specificity have also gone down. Thus, this model is less accurate than the previous one. Therefore, it is necessary to move towards model tuning.

5. Tuning the Model: In this phase, we move towards model optimization by hyperparameter tuning using the grid search algorithm to optimize the cost and $\gamma$ parameters. Ten-fold cross-validation sampling method is used to optimize cost and $\gamma$ parameters. Best performance obtained is 0.3165344 . The grid 
search plot is depicted in Figure 5 below. The darkest region shows the parameter values, which gave the best performance.

6. Selection and Evaluation of best Model: This step now focuses on the selection and evaluation of the best model. On observing the results of confusion matrix presented in Table 6 of the tuned model, we see that 65 and 29 as correctly classified instances, while 44 and 6 are wrongly classified. The accuracy of the model is $65.21 \%$, while the sensitivity and specificity are 91.57 $\%$ and $40.10 \%$ respectively. It indicates that the model is an aggressive one, and it predicts that the customers are satisfied. The positive class defined in the classification problem is 0 , i.e., satisfied. The kappa value is 0.3143 , and it indicates the right fit. At $95 \%$ confidence interval, the predictions are $50.46 \%$ and $78.23 \%$ respectively for each of the two classes. The balanced accuracy for the model is 0.6580 . Results are presented in Table 7 for better understanding. The results are still not much effective. Hence, we now need to further optimize the model by the transformation of the classification data set.

7. Plotting Evaluation Curves: Figure 6 displays the rate of change (ROC) curve for our analysis. The graph is constructed with sensitivity on the vertical axis and 1-specificity on the horizontal. It should indicate that the area in the upper left region provides the most useful discrimination in terms of a cut-off score. The diagonal line, from $(0,0)$ to $(1,1)$, is indicative of an independent variable that discriminates no different from guessing (50/50 chance). The ROC curve is well above this line.

The area under the curve (AUC) is 0.8930 as compared to that of the diagonal line, which is always 0.500 (half the graph). It is depicted in Figure 7. The AUC of 0.8930 more specifically means that of all possible satisfied and dissatisfied customers created from our sample, the model has around $81.6 \%$ of the satisfied customers. Since the $95 \%$ confidence interval $(0.5046,0.7823)$ is greater than 0.500 , we can conclude that our AUC is significantly better than chance. The Chi-square test is also represented in the output, which provides a $p$-value greater than 0.0001 associated with the null hypothesis that our AUC equals 0.8931. Therefore, this test is not significant.

8. Code Transformation for Optimization: Since the previous results were not accurate, the model was further optimized based on the ROC plot obtained, with the main objective in maximizing the value of AUC. For doing this, the first step is to transform our data set. The data set contained values as 0 and 1 . These values were transformed to $\mathrm{X} 0$ and $\mathrm{X} 1$, without affecting the other categories. Then, the AUC model was again optimized using Grid search algorithm. Finally, the prediction was performed on the test data, and the confusion matrix is computed. The confusion matrix presented in Table 8 predicts 62 and 55 as correctly classified instances, while 18 and 9 are wrongly classified. The model resulted in satisfactory results. The accuracy of the model is $81.73 \%$, while the sensitivity and specificity are $87.50 \%$ and $76.10 \%$ respectively. It indicates that the model is an aggressive one, and it predicts that the customers are satisfied. The positive class defined in the classification problem is 0 , i.e., satisfied. The kappa value is 0.6336, and it indicates a good fit. At $95 \%$ confidence interval, the predictions are $67.96 \%$ and $91.26 \%$ respectively for each of the two classes. The balanced accuracy for the model is 0.8175 . The results are presented in Table 9 for better visualization. 
Table 2 Confusion Matrix and Statistics of Initial SVM Model

\begin{tabular}{|c|c|c|}
\hline \multirow{2}{*}{ Prediction class } & \multicolumn{2}{|c|}{ Reference instance } \\
\cline { 2 - 3 } & 0 & 1 \\
\hline 0 & 62 & 26 \\
\hline 1 & 9 & 47 \\
\hline
\end{tabular}

Table 3 Model Prediction Values of Initial SVM Model

\begin{tabular}{|c|l|c|}
\hline Serial number & \multicolumn{1}{|c|}{ Dimensions } & Values \\
\hline 1 & \multicolumn{1}{|c|}{ Accuracy } & 0.7540 \\
\hline 2 & \multicolumn{1}{|c|}{ 95 CI } & $(0.6103,0.8676)$ \\
\hline 3 & No Information Rate & 0.5102 \\
\hline 4 & P-Value [Acc > NIR] & 0.000394 \\
\hline 5 & Kappa & 0.5128 \\
\hline 6 & Mcnemar's Test P-Value & 0.148915 \\
\hline 7 & Sensitivity & 0.8730 \\
\hline 8 & Specificity & 0.6380 \\
\hline 9 & Positive Predicted Value & 0.7000 \\
\hline 10 & Negative Predicted Value & 0.8421 \\
\hline 11 & Prevalence & 0.4898 \\
\hline 12 & Detection Rate & 0.4286 \\
\hline 13 & Detection Prevalence & 0.6122 \\
\hline 14 & Balanced Accuracy & 0.7585 \\
\hline 15 & Positive Class & 0 \\
\hline
\end{tabular}

Table 4 Confusion Matrix and Statistics of New SVM Model

\begin{tabular}{|c|c|c|}
\hline \multirow{2}{*}{ Prediction class } & \multicolumn{2}{|c|}{ Reference instance } \\
\cline { 2 - 3 } & 0 & 1 \\
\hline 0 & 56 & 29 \\
\hline 1 & 15 & 44 \\
\hline
\end{tabular}

Table 5 Model Prediction Values of New SVM Model

\begin{tabular}{|c|l|c|}
\hline Serial number & \multicolumn{1}{|c|}{ Dimensions } & Values \\
\hline 1 & Accuracy & 0.6935 \\
\hline 2 & \multicolumn{1}{|c|}{ 95 \% CI } & $(0.5456,0.8177)$ \\
\hline 3 & No Information Rate & 0.5102 \\
\hline 4 & P-Value [Acc > NIR] & 0.007038 \\
\hline 5 & Kappa & 0.38 \\
\hline 6 & Mcnemar's Test P-Value & 0.301700 \\
\hline 7 & Sensitivity & 0.7907 \\
\hline 8 & Specificity & 0.6017 \\
\hline 9 & Positive Predicted Value & 0.6552 \\
\hline 10 & Negative Predicted Value & 0.7500 \\
\hline 11 & Prevalence & 0.4898 \\
\hline 12 & Detection Rate & 0.3878 \\
\hline 13 & Detection Prevalence & 0.5918 \\
\hline 14 & Balanced Accuracy & 0.6952 \\
\hline 15 & Positive Class & 0 \\
\hline
\end{tabular}




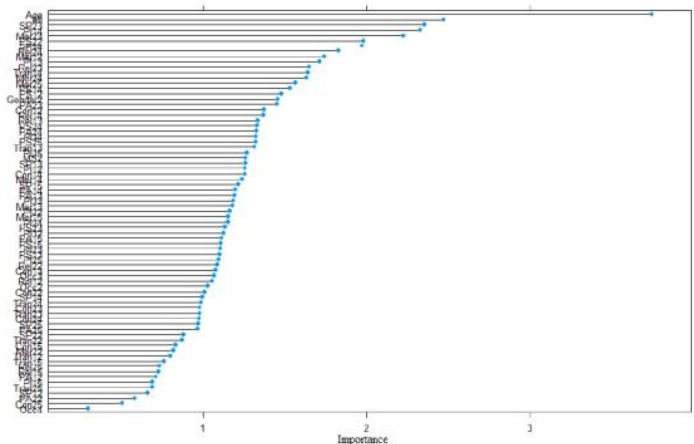

Figure 4 SVM Feature Importance Plot

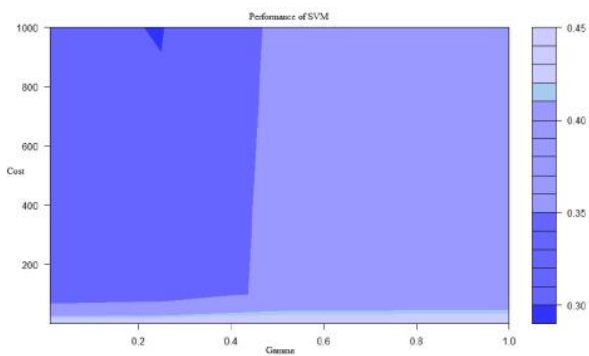

Figure 5 Grid Search Plot

Table 6 Confusion Matrix and Statistics of Tuned Model

\begin{tabular}{|c|c|c|}
\hline \multirow{2}{*}{ Prediction class } & \multicolumn{2}{|c|}{ Reference instance } \\
\cline { 2 - 3 } & 0 & 1 \\
\hline 0 & 65 & 44 \\
\hline 1 & 6 & 29 \\
\hline
\end{tabular}

Table 7 Model Prediction Values of Tuned Model

\begin{tabular}{|c|l|c|}
\hline Serial number & \multicolumn{1}{|c|}{ Dimensions } & Values \\
\hline 1 & Accuracy & 0.6521 \\
\hline 2 & $95 \%$ CI & $(0.5046,0.7823)$ \\
\hline 3 & No Information Rate & 0.5102 \\
\hline 4 & P-Value [Acc > NIR] & 0.030888 \\
\hline 5 & Kappa & 0.3143 \\
\hline 6 & Mcnemar's Test P-Value & 0.003609 \\
\hline 7 & Sensitivity & 0.9157 \\
\hline 8 & Specificity & 0.4010 \\
\hline 9 & Positive Predicted Value & 0.5946 \\
\hline 10 & Negative Predicted Value & 0.8333 \\
\hline 11 & Prevalence & 0.4898 \\
\hline 12 & Detection Rate & 0.4490 \\
\hline 13 & Detection Prevalence & 0.7551 \\
\hline 14 & Balanced Accuracy & 0.6580 \\
\hline 15 & Positive Class & 0 \\
\hline
\end{tabular}




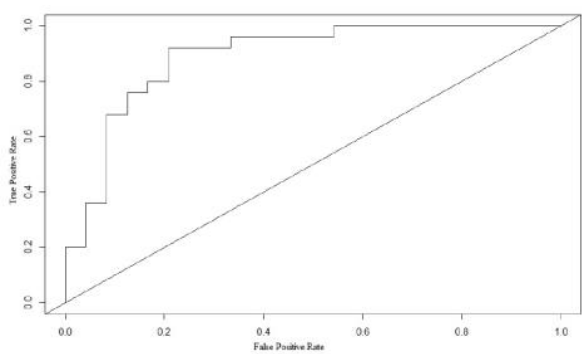

Figure 6 Rate of Change (ROC) Curve

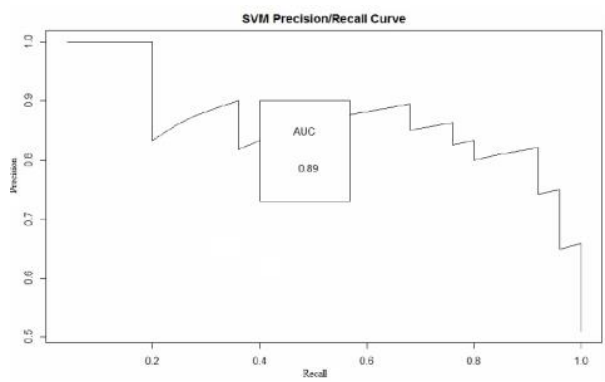

Figure 7 Area under Curve (AUC) Curve

Table 8 Confusion Matrix and Statistics of Transformed Data

\begin{tabular}{|c|c|c|}
\hline \multirow{2}{*}{ Prediction class } & \multicolumn{2}{|l|}{ Reference instance } \\
\cline { 2 - 3 } & $\mathrm{X} 0$ & $\mathrm{X} 1$ \\
\hline $\mathrm{X} 0$ & 62 & 18 \\
\hline $\mathrm{X} 1$ & 9 & 55 \\
\hline
\end{tabular}

Table 9 Model Prediction Values of Transformed Data

\begin{tabular}{|c|l|c|}
\hline Serial number & \multicolumn{1}{|c|}{ Dimensions } & Values \\
\hline 1 & \multicolumn{1}{|c|}{ Accuracy } & 0.8173 \\
\hline 2 & \multicolumn{1}{|c|}{ 95 CI } & $(0.6796,0.8126)$ \\
\hline 3 & No Information Rate & 0.5102 \\
\hline 4 & P-Value [Acc > NIR] & $8.726 \mathrm{e}-06$ \\
\hline 5 & Kappa & 0.6336 \\
\hline 6 & Mcnemar's Test P-Value & 0.505 \\
\hline 7 & Sensitivity & 0.8750 \\
\hline 8 & Specificity & 0.7610 \\
\hline 9 & Positive Predicted Value & 0.7778 \\
\hline 10 & Negative Predicted Value & 0.8636 \\
\hline 11 & Prevalence & 0.4898 \\
\hline 12 & Detection Rate & 0.4286 \\
\hline 13 & Detection Prevalence & 0.5510 \\
\hline 14 & Balanced Accuracy & 0.8175 \\
\hline 15 & Positive Class & X0 \\
\hline
\end{tabular}


The accuracy of the model has increased from $65.21 \%$ to $81.73 \%$. Similarly, the sensitivity and specificity have also increased, which are necessary for a good model. Therefore, the curves for the final model are plotted. Figure 8 displays the ROC curve for our analysis. The graph is constructed with sensitivity on the vertical axis and 1 -specificity on the horizontal. The diagonal line, from $(0,0)$ to $(1,1)$, is indicative of an independent variable that discriminates no different from guessing (50/50 chance). The ROC curve is well above this line and well justifies the accuracy of the model.

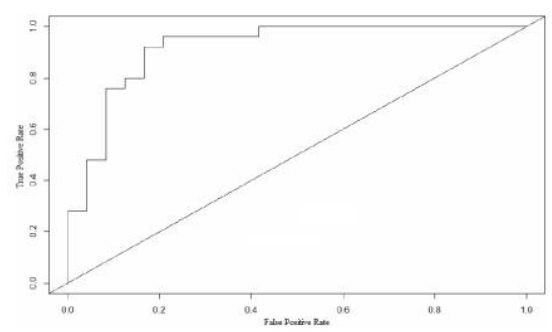

Figure 8 ROC Curve of Final Model

The area under our curve (AUC) is 0.9183 . The AUC of 0.9183 more specifically means that of all possible satisfied or dissatisfied customers created from our sample, the model has around $91 \%$ of the satisfied customers. Since the $95 \%$ confidence interval $(0.6796,0.8126)$ is greater than 0.500 , we can conclude that our AUC is significantly better than chance. The Chi-square test is also represented in the output, which provides a $p$-value $(p<.0001)$ associated with the null hypothesis that our AUC equals 0.9183. Thus, this test is also significant. The AUC curve of the final model is depicted in Figure 9.

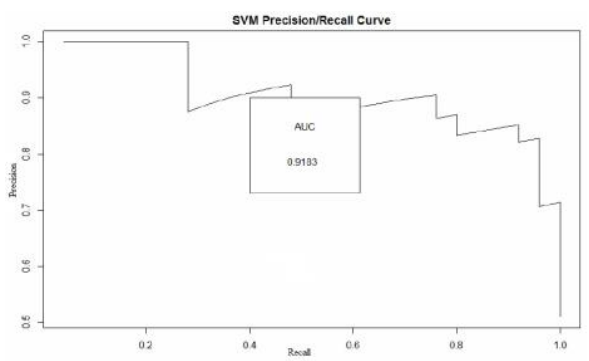

Figure 9 AUC Curve of Final Model

\subsection{Analysis in Accordance with Decision Tree}

Decision trees algorithms belong to supervised machine learning algorithms family. They are used both for classification and regression. These are used mainly for making decisions that would be most useful in reaching some objective and designing a strategy based on these decisions. A decision tree is just a flowchart with several nodes and conditional edges. Each none-leaf node represents a conditional test on one of the features, and the edge represents an outcome of the test. Each leaf node represents a class label where predictions are made for the outcome. Paths from 
the root to all the leaf nodes give us all the classification rules. The various steps involved in decision tree analysis are discussed below.

1. Building Decision Tree Model: The decision tree (DT) algorithm starts with the building of the initial model. The initial model is built with all the features of retail customer satisfaction. The confusion matrix for DT model is presented in Table 10. The confusion matrix predicts 56 and 35 as correctly classified instances, while 47 and 6 are wrongly classified.

2. Model Predictions: As interpreted from the results, the accuracy of the model is $63.37 \%$, while the sensitivity and specificity are $90.38 \%$ and $42.96 \%$ respectively. The positive class defined in the classification problem is 0 , i.e., satisfied. The kappa value is 0.3078, and it indicates a good fit. At $95 \%$ confidence interval, the predictions are $48.49 \%$ and $76.38 \%$ respectively for each of the two classes. The balanced accuracy for the model is 0.6677 . For better understanding, the results are presented in Table 11.

3. Feature Selection: To build a better model, we go for feature selection. Figure 10 shows the feature importance plot. The top 5 important features include Mer12, SP23, Mer 23, Mer25 and PI12.

4. New Model Development and Predictions of Top Features: The new DT model is developed considering the top features based on the variable importance plot. The 5 important variables were identified and are used for building the new model. These variables include Mer1, SP2, PI1, Mer2, Rel2. The confusion matrices for the DT model with different kernel functions are presented in Table 12 below. The confusion matrix predicts 41 and 73 as correctly classified instances, whereas 21 and 9 are wrongly classified.

The accuracy of the new developed DT model is $79.79 \%$, while the sensitivity and specificity are $66.87 \%$ and $89.39 \%$ respectively. It indicates that the model is an aggressive one, and it predicts that the customers are satisfied. The positive class defined in the classification problem is 0, i.e., satisfied. The kappa value is 0.5736 , and it indicates a good fit. At $95 \%$ confidence interval, the predictions are $65.76 \%$ and $89.86 \%$ respectively for each of the two classes. The balanced accuracy for the model is 0.7801 . For better visualization, the results are presented in Table 13. The accuracy of the model has increased, with a substantial increase in specificity and sensitivity.

5. Selection and Evaluation of best Model: Decision tree is shown in Figure 11 is constructed to select the best model.

6. Plotting Evaluation Curves: An ROC curve is a two-dimensional depiction of classifier performance. Figure 12 displays the ROC curve for our analysis. The graph is constructed with sensitivity on the vertical axis and 1-specificity on the horizontal. The diagonal line, from $(0,0)$ to $(1,1)$ is indicative of an independent variable that discriminates no different from guessing (50/50 chance). The ROC curve is well above this line.

The area under our curve (AUC) is 0.7951 as compared to that of the diagonal line, which is always 0.500 . The AUC of 0.7951 more specifically means that of all possible satisfied or dissatisfied customers created from our sample, the model has around $79.51 \%$ of the satisfied customers. Since the $95 \%$ confidence interval $(0.6576,0.8986)$ is greater than 0.500 , we can conclude that our AUC is significantly 
better than chance. The Chi-square test is also represented in the output, which provides a $p$-value $(p<0.0001)$ associated with the null hypothesis that our AUC equals 0.7951. Thus, this test is also significant. The AUC curve is depicted in Figure 13.

Table 10 Confusion Matrix and Statistics of Initial DT Model

\begin{tabular}{|c|c|c|}
\hline \multirow{2}{*}{ Prediction class } & \multicolumn{2}{|l|}{ Reference instance } \\
\cline { 2 - 3 } & 0 & 1 \\
\hline 0 & 56 & 47 \\
\hline 1 & 6 & 35 \\
\hline
\end{tabular}

Table 11 Model Prediction Values of Initial DT Model

\begin{tabular}{|c|l|c|}
\hline Serial number & \multicolumn{1}{|c|}{ Dimensions } & Values \\
\hline 1 & Accuracy & 0.6337 \\
\hline 2 & $95 \%$ CI & $(0.4849,0.7638)$ \\
\hline 3 & No Information Rate & 0.5714 \\
\hline 4 & P-Value [Acc > NIR] & 0.236468 \\
\hline 5 & Kappa & 0.3078 \\
\hline 6 & Mcnemar's Test P-Value & 0.002183 \\
\hline 7 & Sensitivity & 0.9038 \\
\hline 8 & Specificity & 0.4296 \\
\hline 9 & Positive Predicted Value & 0.5429 \\
\hline 10 & Negative Predicted Value & 0.8571 \\
\hline 11 & Prevalence & 0.4286 \\
\hline 12 & Detection Rate & 0.3878 \\
\hline 13 & Detection Prevalence & 0.7143 \\
\hline 14 & Balanced Accuracy & 0.6677 \\
\hline 15 & Positive Class & 0 \\
\hline
\end{tabular}

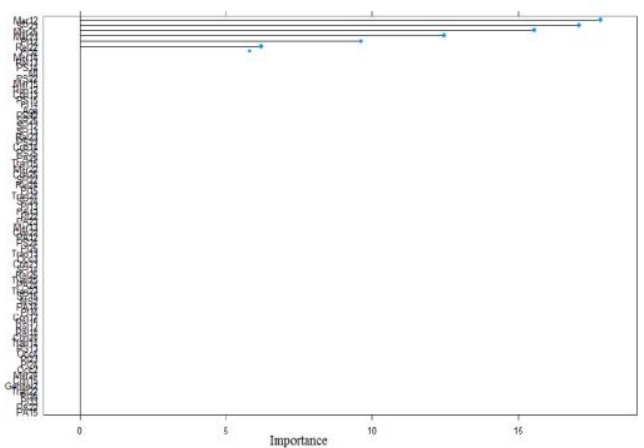

Figure 10 DT Feature Importance Plot 
Table 12 Confusion Matrix and Statistics of New DT Model

\begin{tabular}{|c|c|c|}
\hline \multirow{2}{*}{ Prediction class } & \multicolumn{2}{|c|}{ Reference instance } \\
\cline { 2 - 3 } & 0 & 1 \\
\hline 0 & 41 & 9 \\
\hline 1 & 21 & 73 \\
\hline
\end{tabular}

Table 13 Model Prediction Values of New DT Model

\begin{tabular}{|c|l|c|}
\hline Serial number & \multicolumn{1}{|c|}{ Dimensions } & Values \\
\hline 1 & Accuracy & 0.7979 \\
\hline 2 & $95 \%$ CI & $(0.6576,0.8986)$ \\
\hline 3 & No Information Rate & 0.5714 \\
\hline 4 & P-Value [Acc > NIR] & 0.0008347 \\
\hline 5 & Kappa & 0.5736 \\
\hline 6 & Mcnemar's Test P-Value & 0.3427817 \\
\hline 7 & Sensitivity & 0.6687 \\
\hline 8 & Specificity & 0.8939 \\
\hline 9 & Positive Predicted Value & 0.8235 \\
\hline 10 & Negative Predicted Value & 0.7812 \\
\hline 11 & Prevalence & 0.4286 \\
\hline 12 & Detection Rate & 0.2857 \\
\hline 13 & Detection Prevalence & 0.3469 \\
\hline 14 & Balanced Accuracy & 0.7801 \\
\hline 15 & Positive Class & 0 \\
\hline
\end{tabular}

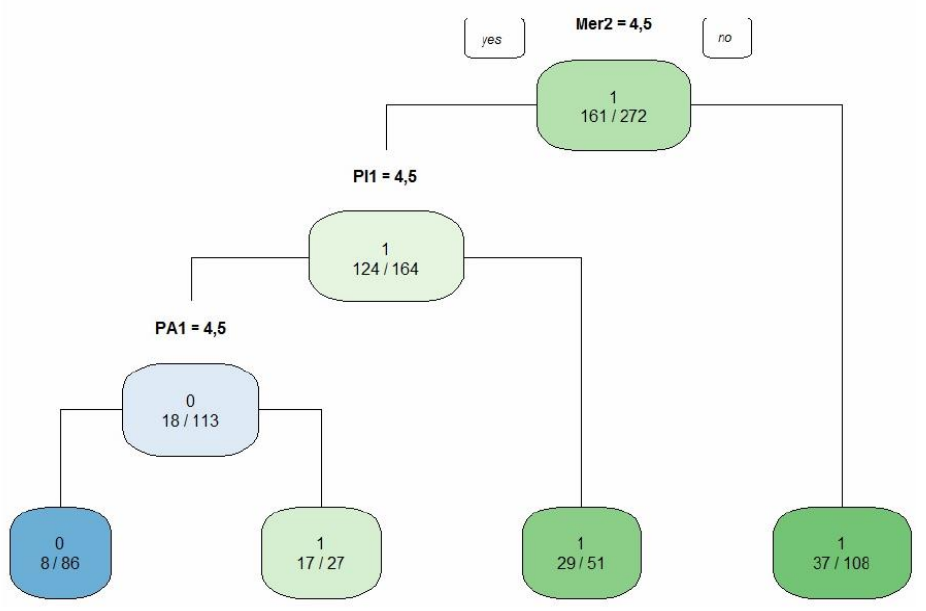

Figure 11 Decision Tree Construction 


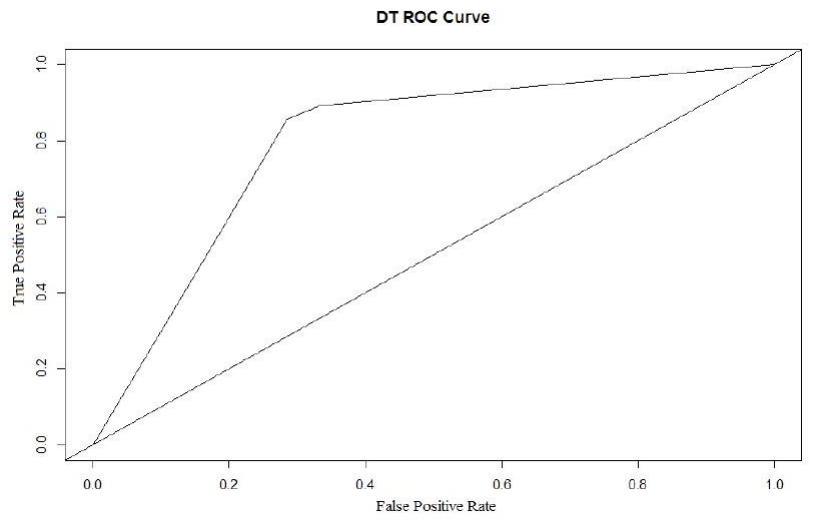

Figure 12 ROC Curve of Decision Tree

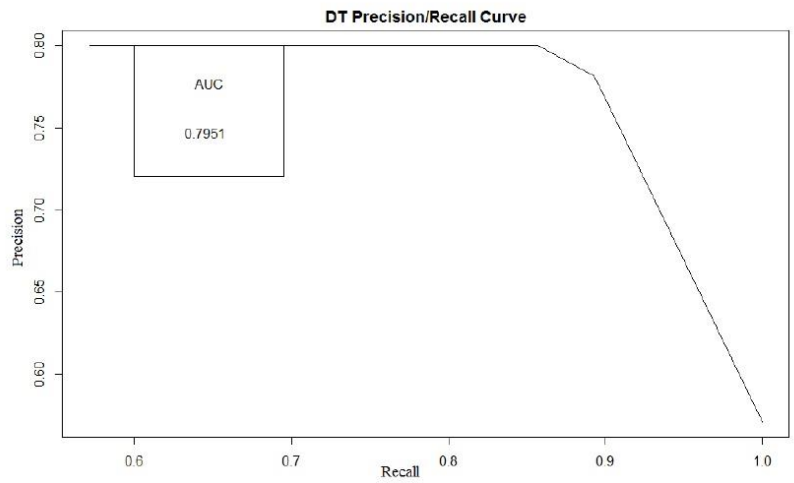

Figure 13 AUC Curve of Decision Tree

\subsection{Comparative Analysis of SVM and Decision Tree}

This section explains a comparative analysis of both techniques. The analysis of both the classification techniques indicated that the SVM generated an optimized result for the problem. Various measures considered for the comparative study are confusion matrix, AUC curve, and ROC curve. The confusion matrix predicted 59 and 54 as correctly classified instances, while 17 and 9 are wrongly classified. It means that a total of twenty-six respondents have been wrongly classified, 17 respondents have been classified as satisfied but are actually dissatisfied, while 9 respondents are satisfied, but are wrongly classified as dissatisfied. The accuracy of the model is $81.73 \%$, which is well reaching the standard. The area under our curve is 0.9183 . It indicates that the model has around $91 \%$ of satisfied customers. AUC is significantly better than chance since the $95 \%$ confidence interval $(0.6796,0.8126)$ is greater than 0.500 . The Chi-square test as represented in the output provides a pvalue $(p<.0001)$, which clearly states the significant association with the null hypothesis AUC equals 0.9183.

The decision tree model generated a lesser impressive response in comparison to SVM. The confusion matrix predicts 41 and 73 as correctly classified instances, 
while 21 and 9 are wrongly classified. The accuracy of the model is $79.79 \%$, which is less than the classification accuracy of SVM. The decision tree states that the significant, influential variables are "This store has a wide assortment of merchandise available for its customers; the behavior of employees in this store instills confidence in customers; and this store has modern-looking equipment and fixtures (PA1)". The area under our curve is 0.7951. Thus the model has around $79.51 \%$ of the satisfied customers. The $95 \%$ confidence interval and p-value are well reaching the standard. Thus there is an association. The study stated that both the models are aggressive and both of them predict that the customers are satisfied, though the accuracy varies in both the cases. The positive class defined in both the classification problem is 0 , i.e., satisfied. Thus it can be inferred that retail stores must recognize service quality as a crucial marketing tool to develop customer satisfaction, which in turn would result in profitability for the firm. The retailers should frequently assess customer's perceptions of service quality and develop appropriate policies to meet their customer's expectations. The future studies can be useful in assessing the expectation measures and perception measures for the major dimensions to ascertain whether gaps between these measures are significant in retail service quality.

\section{Managerial Implications}

Indian retail industry stands on the cusp of a new future driven by growing consumption, improving infrastructure, and supportive regulation. Retailers are very bullish about growth prospects in India, and several are indeed delivering doubledigit growth. Thus, retailers should realize that to grow profitably and achieve scale and relevance; they need to do things differently in the future. The retail service quality plays a significant role in such a context in attracting new customers, retaining existing customer, and creating confidence among the large customer base which India provides.

The findings of this study intend to give an insight into the Indian retail service quality. Service quality is an essential marketing tool for retail stores to develop a competitive edge in the market. It is done in retail stores by learning about their customer's consumption experiences. The present study contributes to the literature on retail service quality by identifying the essential dimensions of retail service quality that ensures customer satisfaction. The results of the study have identified five major dimensions of the retail service quality that satisfies the customers. The retailers can focus on these dimensions and develop strategies to satisfy the customers. It minimizes the gap that is prevailing between the perceived service quality and actual service quality provided to customers. Hence this is an effective way to enhance customer satisfaction concerning important service quality features. The managers can use the results of this study to increase their understanding of which service quality dimensions has the most active association with overall customer satisfaction.

\section{Conclusion}

In today's ever-increasing competitive business environment, it is imperative for a retail firm to target marketing efforts at the right group of customers. The paper 
focuses on the classification of retail customers into the classes of satisfied and dissatisfied using R-project. The research work presents a comparative study of SVM and decision tree classification techniques used to classify retail customers as satisfied and dissatisfied according to retail service quality dimensions. At the initial stage, factor analysis is carried out for which a questionnaire survey is conducted with a sample being selected from multiple apparel stores located in different areas of the state of Odisha. Simple random sampling is used to select the sample of retail shoppers visiting retail clothing chain of stores of the state. Seventeen variables besides the demographic variables are considered for the study. The data was further cleaned and transformed into a suitable and readable format for the data mining tool to generate. After that, the variables of retail service quality generated from factor analysis are analyzed by developing a code snippet in R-Studio separately for both classification techniques. From the comparative study, it is found that SVM performs better results as compared to the decision tree technique. Besides, this study may be important for international retailers planning to enter the Indian market. It becomes more important as the Government of India is planning to open foreign direct investment in the retail sector to fuel the growth. Again, this study can be extended to several other retail segments, and generic factors for Indian retail service quality can be discovered.

\section{Limitations and Future Research}

The present study involves some limitations that need to be acknowledged. First, the research was restricted to four major cities of Odisha and to organized apparel stores. The results obtained may not be generalizable to the country as a whole. Future research needs to extrapolate the results to the other retail formats, product categories and cities. Secondly, the small sample size of 321 may also be error-prone. Future research in retail service quality evaluation should examine a larger sample size which would enable more reliable analysis across different demography of respondents. Other classification algorithms such as K-NN, Naive Bayes can also be implemented.

\section{References}

1. Acharjya, D. P., and Das, T. K. (2017), A framework for attribute selection in marketing using rough computing and formal concept analysis, IIMB management review, Vol.29 (No.2), pp.122-135.

2. Acharjya, D., and Anitha, A. (2017), A comparative study of statistical and rough computing models in predictive data analysis, International Journal of Ambient Computing and Intelligence, Vol. 8 (No.2), pp.32-51.

3. Aktepe, A., Ersöz, S., and Toklu, B. (2015), Customer satisfaction and loyalty analysis with classification algorithms and Structural Equation Modeling, Computers \& Industrial Engineering, Vol. 86, pp. 95-106

4. Anitha, A., and Acharjya, D. P. (2018), Crop suitability prediction in Vellore District using rough set on fuzzy approximation space and neural network, Neural Computing and Applications, Vol.30 (No.12), pp.3633-3650. 
5. Anitha, A., and Acharjya, D. P. (2016), Customer choice of super markets using fuzzy rough set on two universal sets and radial basis function neural network, International Journal of Intelligent Information Technologies, Vol.12 (No. 3), pp.20-37.

6. Anyanwu, M. N., and Shiva, S. G. (2009), Comparative analysis of serial decision tree classification algorithms, International Journal of Computer Science and Security, Vol.3(No.3), pp.230-240.

7. Bedi, M. (2010), An integrated framework for service quality, customer satisfaction and behavioral responses in Indian banking industry - A comparison of public and private sector banks, Journal of Services Research, Vol.10(No.1), pp.157-172.

8. Berry, L. L., Parasuraman, A., and Zeithaml, V. A. (1988), SERVQUAL: A multiple-item scale for measuring consumer perceptions of service quality, Journal of Retailing, Vol.64 (No.1), pp.12-40.

9. Bose, I., and Mahapatra, R. K. (2001), Business data mining - a machine learning perspective. Information \& management, Vol.39 (No.3), pp.211-225.

10. Boser, B. E., Guyon, I. M., and Vapnik, V. N. (1992)., A training algorithm for optimal margin classifiers. In Proceedings of the fifth annual workshop on Computational learning theory, pp.144-152.

11. Burges, C. J. (1998), A tutorial on support vector machines for pattern recognition, Data Mining and Knowledge Discovery, Vol.2 (No.2), pp.121-167.

12. Cortes, C., and Vapnik, V. (1995), Support vector networks, Machine Learning, Vol.20 (No.3), pp.273-297.

13. Dabholkar, P. A., Thorpe, D. I., and Rentz, J. O. (1996), A measure of service quality for retail stores: scale development and validation, Journal of the Academy of Marketing Science, Vol.24 (No.1), pp.3-16.

14. Das, A., Kumar, V. and Saha, G. C. (2010), Retail service quality in context of CIS countries, International Journal of Quality \& Reliability Management, Vol.27 (No.6), pp.658-683.

15. Deb, R., and Liew, A. W. C. (2015), Incorrect attribute value detection for traffic accident data, In Proceedings of IEEE International Joint Conference on Neural Networks, pp.1-7.

16. Fayyad, U. M., Piatetsky-Shapiro, G., Smyth, P., and Uthurusamy, R. (1996), Advances in knowledge discovery and data mining. 1-34, AAAI press, Menlo Park, California.

17. Gupta, A., Mohammad, A., Syed, A., and Halgamuge, M. N. (2016), A comparative study of classification algorithms using data mining: Crime and accidents in Denver city the USA, International Journal of Advanced Computer Science and Applications, Vol.7 (No.7), pp.374-381.

18. Han, J., Pei, J., and Kamber, M. (2011), Data mining: concepts and techniques. Morgan Kaufmann Publishing, USA.

19. Hornik, K., Meyer, D., and Karatzoglou, A. (2006), Support vector machines in R, Journal of statistical software, Vol.15 (No.9), pp.1-28.

20. Kaul, S. (2007), Measuring retail service quality: examining applicability of international research perspectives in India, Vikalpa, Vol.32 (No.1), pp.15-26. 
21. Kim, S., \& Jin, B. (2002), Validating the retail service quality scale for US and Korean customers of discount stores: an exploratory study, Journal of Services Marketing, Vol.16 (No.3), pp. 223-237.

22. Kohavi, R. (1996)., Scaling Up the Accuracy of Naive-Bayes Classifiers: A Decision-Tree Hybrid. In Proceedings of Knowledge Discovery Databases, 96, pp.202-207

23. Ladhari, R. (2008), Alternative measures of service quality: a review, Managing Service Quality: An International Journal, Vol.18 (1), pp.65-86.

24. Lai, F., Griffin, M., and Babin, B. J. (2009), How quality, value, image, and satisfaction create loyalty at a Chinese telecom, Journal of Business Research, Vol.62 (No.10), pp. 980-986.

25. Larose, D. T. (2014), Discovering knowledge in data: an introduction to data mining, John Wiley \& Sons, NJ, USA

26. Lee, J. H., \& Lin, C. J., Automatic model selection for support vector machines. (2000).

27. Linoff, G. S., and Berry, M. J. (2011), Data mining techniques: for marketing, sales, and customer relationship management. John Wiley \& Sons, Hoboken, New Jersey.

28. McDonnell, A., Lamare, R., Gunnigle, P., and Lavelle, J. (2010), Developing tomorrow's leaders-Evidence of global talent management in multinational enterprises, Journal of World Business, Vol.45 (No.2), pp. 150-160.

29. Mehta, S. C., Lalwani, A. K., and Li Han, S. (2000), Service quality in retailing: relative efficiency of alternative measurement scales for different productservice environments, International Journal of Retail \& Distribution Management, Vol. 28 (No. 2), pp. 62-72.

30. Ngai, E. W., Xiu, L., and Chau, D. C. (2009), Application of data mining techniques in customer relationship management: A literature review and classification, Expert systems with applications, Vol. 36 (No.2), pp. 2592-2602.

31. Parikh, D. (2006), Measuring retail service quality: an empirical assessment of the instrument, Vikalpa, Vol.31 (No.2), pp. 45-56.

32. Qian, Y., and Ju, C. (2009), Study on Retail Customer Classification Based on Support Vector Machine, In Proceedings of IEEE International Workshop on Intelligent Systems and Applications, pp.1-5.

33. Rai, A. K., and Srivastava, M. (2012), Customer loyalty attributes: A perspective, NMIMS management review, 22, pp.49-76.

34. Rathi, R., and Acharjya, D. P. (2018)., A framework for prediction using rough set and real coded genetic algorithm, Arabian Journal for Science and Engineering, Vol. 43(No. 8), pp.4215-4227.

35. Shaw, M. J., Subramaniam, C., Tan, G. W., and Welge (2001), M. E., Knowledge management and data mining for marketing. Decision support systems, Vol.31(No.1), pp.127-137.

36. Shemwell, D. J., Yavas, U., and Bilgin, Z. (1998), Customer-service provider relationships: an empirical test of a model of service quality, satisfaction and relationship-oriented outcomes. International Journal of Service Industry Management, Vol.9 (No.2), pp.155-168. 
37. Sivadas, E., and Baker-Prewitt, J. L. (2000), An examination of the relationship between service quality, customer satisfaction, and store loyalty, International Journal of Retail \& Distribution Management, Vol. 28(No. 2), pp.73-82.

38. Spreng, R. A., and Mackoy, R. D. (1996), An empirical examination of a model of perceived service quality and satisfaction. Journal of retailing, Vol.72 (No.2), pp. 201-214.

39. Sumathi, S., and Sivanandam, S. N. (2006), Introduction to data mining and its applications. 29, Springer Verlag, Heidelberg, USA.

40. Vapnik, V. N., and Chervonenkis, A. J. (1974), Theory of pattern recognition, Nauka, Moscow.

41. Vapnik, V., Golowich, S. E., and Smola, A. J. (1997), Support vector method for function approximation, regression estimation and signal processing, In Advances in neural information processing systems, pp.281-287.

42. Verhoef, P. C., Reinartz, W. J., and Krafft, M. (2010), Customer engagement as a new perspective in customer management Journal of Service Research, Vol.13 (3), pp. 247-252.

43. Wong, A., and Sohal, A. (2003), Service quality and customer loyalty perspectives on two levels of retail relationships, Journal of Services Marketing, Vol.17 (No.5), pp.495-513.

\section{Acknowledgements}

The authors would like to thank the anonymous reviewers and the Editor-in-Chief Dr. Omprakash K. Gupta for their insightful comments and suggestions

\section{About Our Authors}

Sreekumar has a doctorate in management and is presently working as Professor at Rourkela Institute of Management Studies, Rourkela, India. His areas of interest include application of data envelopment analysis, multicriteria decision making, and decision making in fuzzy environments. He has 27 years of teaching experience in the areas of decision science. He has published more than 60 research papers in various international and national conferences and journals. He has also authored two textbooks. He is the reviewer of several international journals. In addition, he is a Visiting Faculty member of many business schools in India.

Rema Gopalan is presently working as an Assistant Professor in IFIM Business School, Bengaluru and has more than eleven years of academics, research and administrative experience. She has completed Masters in Business Administration in Marketing and Human Resource from Biju Patnaik University of Technology, Odisha. She qualified National Eligibility Test conducted by University Grant Commission, India. She completed her Doctorate of Philosophy in Management (Marketing) from Sambalpur University, Odisha. Her research interest includes Multi Criteria Decision Making, Service Quality Evaluation, Machine Learning, Business Analytics and related areas of marketing. She has published around thirteen research papers in various international and national journals and conferences. 
Mayuri Shah is currently working as a Research Assistant at MICA, Ahmedabad in Business Management Area. She also worked as a research associate at Indian Institute of Management, Ahmedabad (IIMA) in Marketing Area after completing her post-graduation from Rourkela Institute of Management Studies, Rourkela. Her areas of interest include statistical decision making, digital marketing and social media marketing. Presently she is working on Data modelling with Python" and "Writing and Publishing Compact Cases".

D. P. Acharjya received his M.Sc. from NIT, Rourkela, India; M. Tech. in computer science from Utkal University, India and obtained his Ph.D. in Computer Science from Berhampur University, India. He is presently working as a Professor in the School of Computer Science and Engineering at VIT-Vellore, India. He has authored 80 international, national papers, book chapters, and four books to his credit. In addition, he has edited seven books with international publishers like Springer, CRC Press, and IGI Global, USA. He has been awarded the Gold Medal in M.Sc. Besides, he has also awarded with Eminent Academician Award; Outstanding Educator and Scholar Award; The Best Citizens of India Award; and Bharat Vikas Award. His research interest includes rough sets, knowledge representation, machine learning and business intelligence. Dr. Acharjya is associated with many professional bodies like CSI, ISTE, IMS, AMTI, ISIAM, OITS, IACSIT, CSTA, and IAENG. 